\section{Vessel Type, Closure, and Explant Orientation Influence in Vitro Performance of Five Woody Species}

\author{
M.T. McClelland and M.A.L. Smith \\ Department of Horticulture, University of Illinois, Urbana, IL 61801
}

Additional index words. microculture, tissue culture, Amelanchier spicata, Acer rubrum, Forsythia $\mathbf{x}$ inter-media, Malus $\times$ domestica, Betula nigra

Abstract. Effects of three variables (vessel type, closure, and explant orientation) on microcutting quality were investigated using five woody species [low shadblow, Amefanchier spicata (Lam.) C. Koch (Syn. A. humilus Wieg.); red maple, Acer rubrun L. 'Red Sunset'; border forsythia, Forsythia xintermedia Zab. 'Sunrise'; apple, Malus xdomestica Borkh. 'McIntosh'; river birch, Betula nigra L.]. Uniform shoot explants were oriented vertically or horizontally in three vessel types $(60-\mathrm{ml}$ glass culture tubes, 200-ml glass baby food jars, and 350-ml polypropylene GA7 vessels) with and without a Parafilm seal. Visual density per explant obtained by image analysis was increased in larger vessel types, and significantly more shoots were produced from horizontally placed explants. Closure treatments influenced microshoot quality, but trends were species specific. Overall, horizontal explant orientation in larger vessels wthout parafilm maximized shoot response for most of the species studied. In vitro rooting of microcuttings was significantly enhanced in larger vessels.

Shoot length, proliferation rate, and fresh weight of micropropagated plants have varied according to culture vessel type (Mackay and Kitto, 1988; Monette, 1986). Mackay and Kitto (1988) demonstrated the ratio of explant number to volume of medium could cause differences in fresh weight and proliferation rates, and vessel closure treatments affected culture proliferation rates, shoot yield, and plant morphology according to other reports (Ivanicka, 1987; Webb et al., 1986). The gaseous atmosphere in vitro, and, consequently, the quality of micropropagated plants, can be significantly affected by closure around vessel caps (Lentini et al., 1988). Explant orientation may modify both the number and length of proliferated shoots (Mackay and Kitto, 1988; Sutter and Barker, 1985). This study examines the effects of vessel type, closure, and explant orientation on in vitro microshoot development and rooting capacity for a range of commercially micropropagated woody plant genera, using production methods that parallel commercial

Received for publication 10 Aug. 1989, Wc thank M. Meyer, Jr., and Mark Zilis for donating some of the original stock cultures for test plants used in these experiments. This project supported by the Agricultural Experiment Station Project 650363 and the Lilly Endowment. The cost of publishing this paper was defrayed in part by the payment of page charges. Under postal regulations, this paper therefore must be hereby marked $a d$ vertisement solely to indicate this fact.

\section{standards.}

Plant material. Established, proliferating shoot cultures of Amelanchier, Acer, Forsythia, Malus, and Betula grown in GA7 vessels (Magenta Corp., Chicago) were used as explant sources for all experiments. Before treatment, stock microcultures from the previous subculture were grown for 4 to 8 weeks. Uniform two- to three-node explants were taken from cultures; leaves, petioles, and apical buds were removed. Explants were $\approx 1.0$ to $2.5 \mathrm{~cm}$ across, depending on the

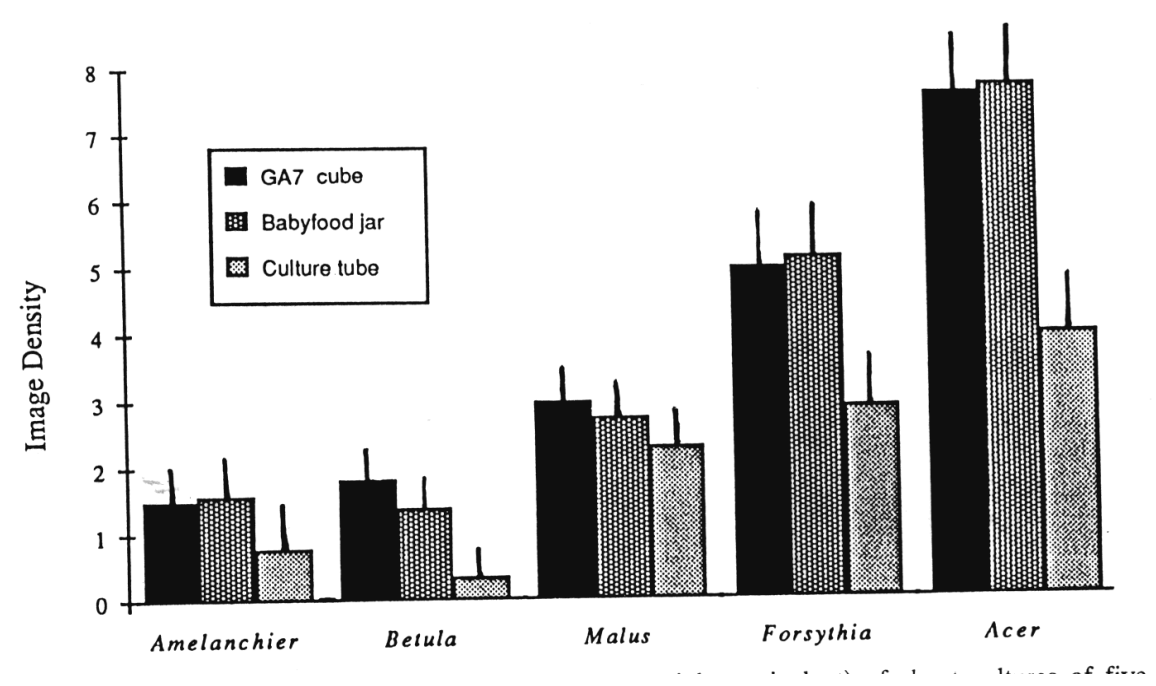

Fig. 1. Effect of vessel type on image density (fresh weight equivalent) of shoot cultures of five woody plant species. The vertical line above each bar represents $+1.0 \mathrm{SE}$. genus. Explants of Amelanchier, Acer, and Forsythia were subcultured onto a modified MS salts medium (Murashige and Skoog, 1962) containing (in $\mu \mathrm{M}$ ) $1.0 \mathrm{~N}$ - (phenylmethyl)-1H-purine-6-amine (BA), $0.05 \mathrm{~N}$ phenyl-N'-1,2,3-thiadiazol-5-ylurea (TDZ), and $0.051 \mathrm{H}$-indole-3-butyric acid (IBA), with (in g.liter ${ }^{-1}$ ) 25 sucrose, 100 myoinositol, and (in mg.liter ${ }^{-1}$ ) 5.0 nicotinic acid, 1.0 pyridoxine- $\mathrm{HCl}$, and 0.5 thiamine $\cdot \mathrm{HCl}$ (Kerns and Meyer, 1986). The $\mathrm{pH}$ was adjusted to 5.8; 7.0 g Difco bacto agar/liter was added before autoclaving. Explants of Malus were subcultured onto a similar medium containing $8.8 \mu \mathrm{M} \mathrm{BA}$ and $0.5 \mu \mathrm{M}$ 1-naphthaleneacetic acid (NAA). Explants of Betula were subcultured onto Woody Plant Medium (WPM; Lloyd and McCown, 1980) containing $2.2 \mu \mathrm{M} \mathrm{BA}$. Cultures were maintained at $22 \pm 2 \mathrm{C}$ under a $24-\mathrm{hr}$ photoperiod of 50 to $60 \mu \mathrm{mol} \cdot \mathrm{s}^{-1} \cdot \mathrm{m}^{-2}$ provided by cool-white fluorescent lamps.

Physical microenvironmental treatments. Explants were subcultured into either 350ml GA7 polypropylene vessels, 200-ml glass jars (baby food), or 60-ml glass culture tubes with medium surface areas of $39.6,23.2$, or $3.7 \mathrm{~cm}^{2}$, respectively. To maintain uniform explant : medium ratios, three explants were grown on $45 \mathrm{ml}$ of medium in GA7 vessels, two on $30 \mathrm{ml}$ of medium in baby food jars, and one on $15 \mathrm{ml}$ of medium in culture tubes. Explants were either oriented vertically or horizontally on the medium. Vessel closures were translucent polypropylene vessel caps manufactured specifically for the type of vessel (Magenta). Half of the replicate cultures were sealed with parafilm around the edge of the vessel and cap, the rest were not sealed with parafilm. 


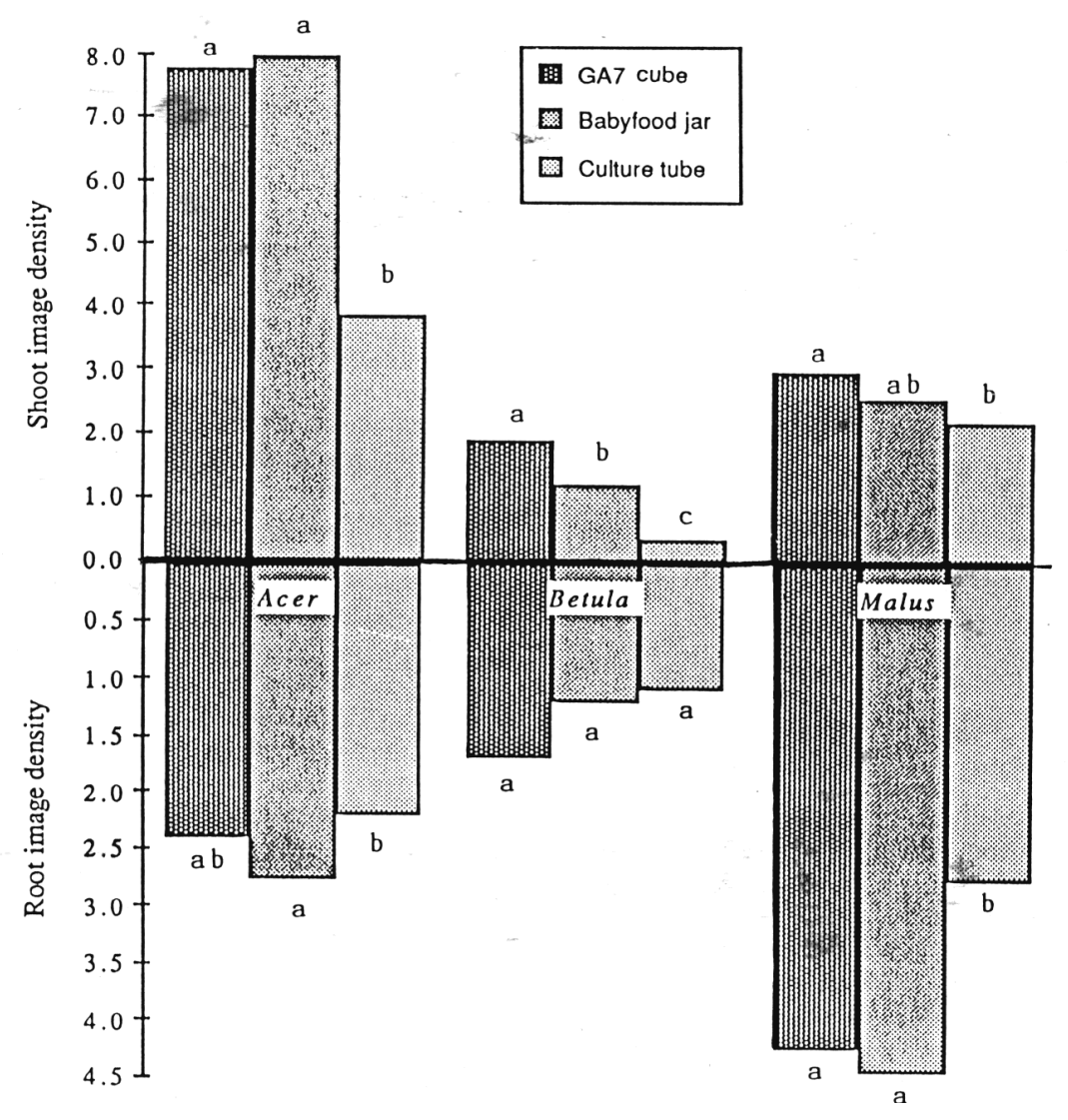

Fig. 2. Effect of vessel type on shoot and root image density (fresh weight equivalent). Mean separation by GLM procedure and LSD ( $t$ test) within plant species by vessel type, $P=0.05$. Histograms represent shoot and root visual density averages of 40 plants.

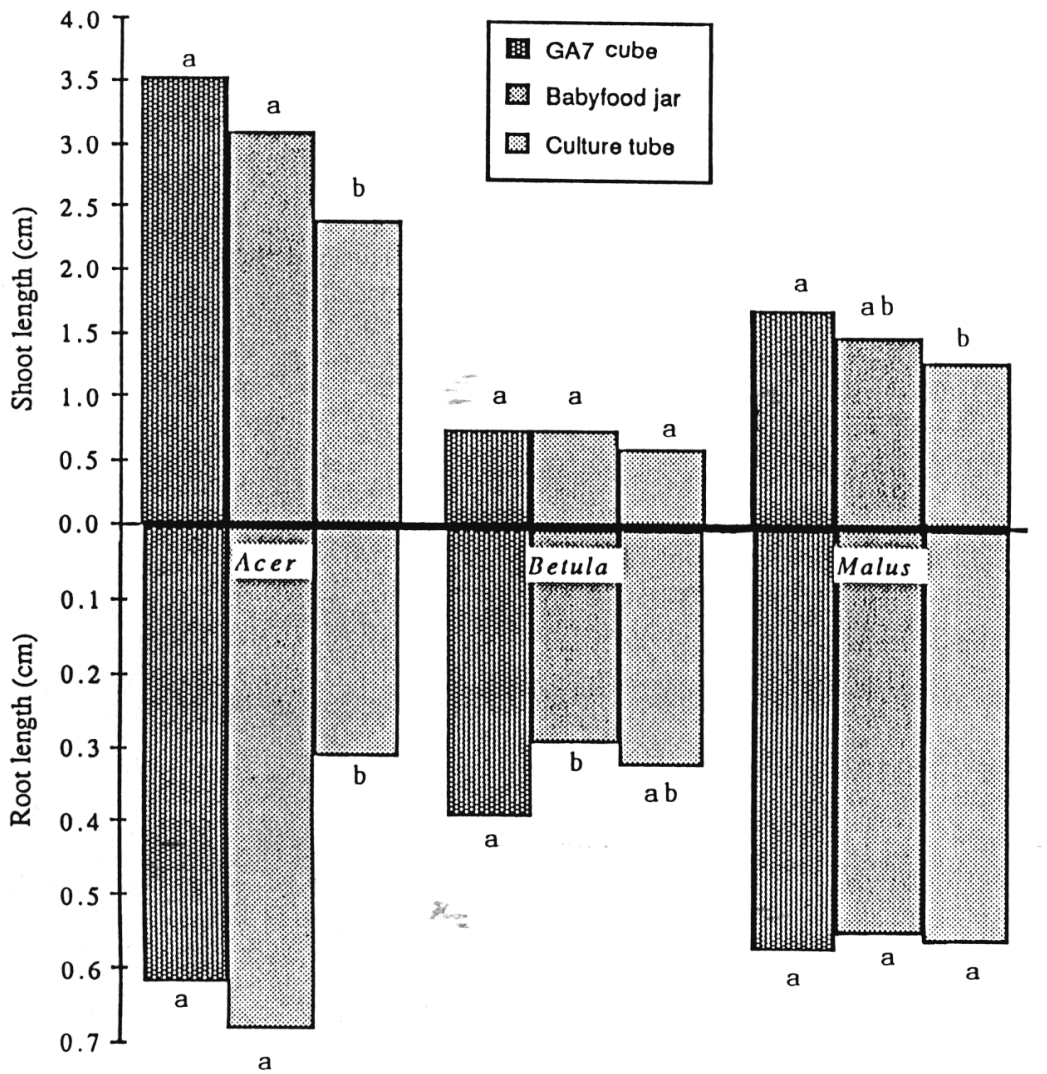

Fig. 3. Effect of vessel type on shoot and root length. Mean separation by GLM procedure and LSD ( $t$ test) within plant species by vessel type, $P=0.05$. Histograms represent shoot and root length averages of 40 plants.
Evaluation methods. After a standard growth period (4 to 6 weeks for Forsythia and Malus, 6 to 7 weeks for Amelanchier, Acer, and Betula), data on shoot length and image density were collected through an adaptation of microcomputerized video image analysis. This imaging technique was specifically developed for microcultured plant measurements and has been verified by strong correlation with destructive measurements of shoot culture growth (shoot length and fresh weight) (Smith et al., 1989). Image density was determined by the number and value (gray level or visual density) of all pixels (image points) in the digitized video image of each sample. The image analysis technique also facilitated evaluation of new growth, excluding any contribution from the original explant material or callus. Visual evaluations and shoot number counts supplemented the imaging data.

Immediately following evaluation of shoot proliferation, 20 uniform microcuttings (2.0 to $2.5 \mathrm{~cm}$ long) of Acer, Betula, and Malus from each of the previous treatments were excise and inserted vertically in culture tubes containing $20 \mathrm{ml}$ of rooting medium. Closures for culture tubes used in rooting were not sealed with parafilm. Cuttings of Malus and Acer were rooted in half-strength MS medium containing IBA (7.4 $\mu \mathrm{M}$ for Malus and $1 \mu \mathrm{M}$ for Acer). Betula was rooted in full-strength WPM 'without growth regulators. Only $15 \mathrm{~g}$ sucrose/liter was used in all rooting media. The relative rooting response between different treatments was determined after 2 weeks by image analysis to measure root length and visual density of the new adventitious root system.

Proliferation treatments were arranged in a completely randomized design that included 10 replications of each vessel-explant orientation-closure combination for each of the five woody species. For vessels containing more than one explant, data were averaged on a per explant basis before statistical analysis. Treatment effects were compared with unpaired $t$ tests and means separated by LSD and GLM procedures (SAS Institute, 1985).

Influence of vessel type. Image density (fresh weight equivalent) was significantly greater for shoot cultures of all test species grown in the two larger vessels than in the culture tubes (Fig. 1). Response of shoot length and shoot number, as a function of vessel type, varied with individual species (Table 1). Leaf area increased as vessel-type growing area increased for all the plant species tested. GA7 vessels and baby food jars not only produced microcuttings of substantially greater shoot height and image density per explant than did explants in culture tubes, but these microcuttings also rooted better than those grown in culture tubes, as measured by root system visual density and root length (Figs. 2 and 3).

Influence of vessel closure. Plant growth responses in relation to the presence of a parafilm seal around the vessel cap (measured by shoot length, image density, and shoot number) were species specific. Vessels 


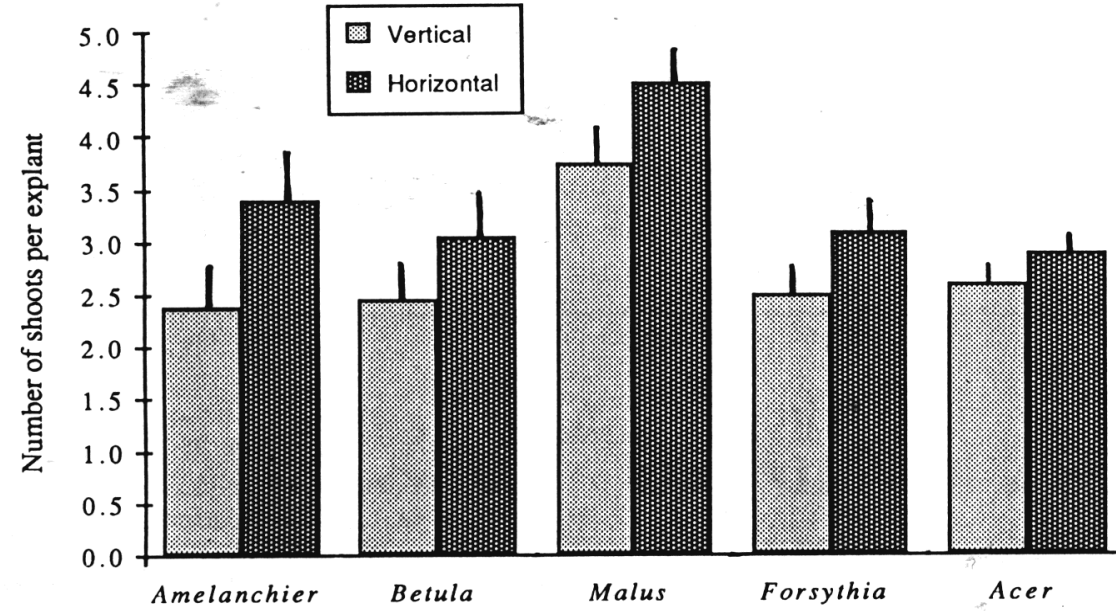

Fig. 4. Effect of explant orientation on shoot number per explant for five woody plant species. The vertical line above each bar represents $+1.0 \mathrm{SE}$.

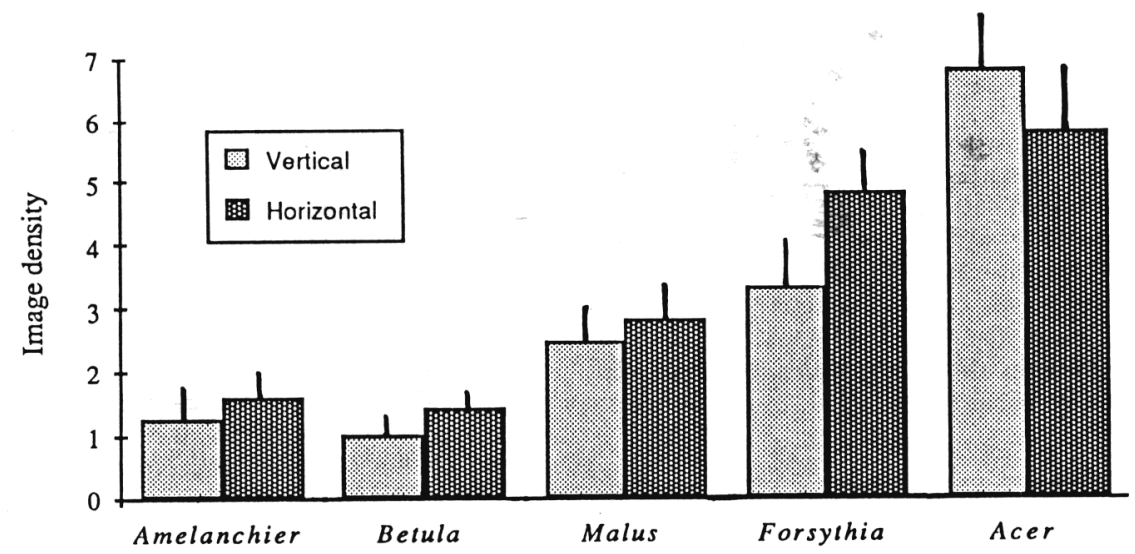

Fig. 5. Effect of explant orientation on image density (fresh weight equivalent) for five woody plant species. The vertical line above each bar represents $+1.0 \mathrm{SE}$.

Table 1. Effect of vessel type on shoot length and number in proliferating cultures of five woody plant species.

\begin{tabular}{|c|c|c|c|c|c|}
\hline \multirow[b]{2}{*}{ Vessel type } & \multicolumn{5}{|c|}{ Species } \\
\hline & Amelanchier & Betula & Malus & Forsythia & Acer \\
\hline & \multicolumn{5}{|c|}{ Shoot length $(\mathrm{cm})$} \\
\hline GA7 & $1.2 \mathrm{a}^{2}$ & $-0.8 \mathrm{a}$ & $1.7 \mathrm{a}$ & $6.2 \mathrm{ab}$ & $3.5 \mathrm{a}$ \\
\hline Baby food jar & $1.4 \mathrm{a}$ & $-0.8 \mathrm{a}$ & $1.5 \mathrm{ab}$ & $5.6 \mathrm{~b}$ & $3.1 \mathrm{a}$ \\
\hline \multirow[t]{2}{*}{ Culture tube } & $1.4 \mathrm{a}$ & $0.7 \mathrm{a}$ & $1.4 \mathrm{~b}$ & $6.4 \mathrm{a}$ & $2.4 \mathrm{~b}$ \\
\hline & \multicolumn{5}{|c|}{ Shoot no./explant } \\
\hline GA7 & $4.1 \mathrm{a}$ & $2.8 \mathrm{a}$ & $4.4 \mathrm{ab}$ & $2.9 \mathrm{a}$ & $2.6 \mathrm{~b}$ \\
\hline Baby food jar & $2.0 \mathrm{~b}$ & $2.8 \mathrm{a}$ & $3.7 \mathrm{~b}$ & $3.0 \mathrm{a}$ & $3.3 \mathrm{a}$ \\
\hline Culture tube & $2.3 \mathrm{~b}$ & $2.8 \mathrm{a}$ & $4.6 \mathrm{a}$ & $2.6 \mathrm{a}$ & $2.4 \mathrm{~b}$ \\
\hline
\end{tabular}

'Mean separation within columns for shoot length and shoot number by LSD, $P=0.05$. Each value represents the mean of 40 explants.

sealed with parafilm had higher condensation (due to greater relative humidity), which led to flaccid and often vitrified shoots for some species (in particular, Acer and Forsythia). This occurrence caused a significant reduction in visual density for shoots in parafilm-sealed vessels for both species. Only shoots of Betula showed evidence of enhanced shoot length and density in the highhumidity environment in vessels sealed with parafilm.

Influence of explant orientation. Horizontal explant orientation produced the most shoots per explant (Fig. 4) and maximized vessels to lead to production of a shoot with greater leaf area may be important for many woody plants, since rooting capacity is governed, in part, by the concentration of rooting cofactors produced in the leaves (MacDonald, 1986).

Parafilm is often used in commercial production, both to reduce the incidence of contamination and prevent premature dehydration of tissue culture media (Binding and Krumbiegel-Schroeren, 1984; Thorpe and Patel, 1984). Although Parafilm was not a factor in preventing contamination for these experiments (minimal contamination occurred), the presence of the seal favored development of shoots produced by Betula. The detrimental effects of parafilm in this study (vitrification and flaccidity) may be a consequence of both the higher microculture humidity and inhibition of gaseous exchange (Bottcher et al., 1988; Lentini et al., 1988; Perl et al., 1988; Thorpe and Patel, 1984; Webb et al., 1986).

The general lack of significant treatment differences for Amelanchier may be due, in part, to the rosette growth pattern typical for this species, which obscures growth differences. The effect of parafilm was not significant in most instances, but it becomes more pronounced after several repeated subcultures under the same closure treatment (data not presented). This study emphasizes the effect of microenvironment on in vitro performance of several species. The reasons for the vessel effects, in particular, warrant further study.

\section{Literature Cited}

Binding, H. and G. Krumbiegel-Schroeren. 1984 Clonal propagation: Shoot cultures, p. 43-48. In: I.K. Vasil (ed.). Cell culture and somatic cell genetics of plants. vol. 1. Academic, New York.

Bottcher, I., K. Zoglauer, and H. Goring. 1988. Induction and reversion of vitrification of plants cultured in vitro. Physiol. Plant. 72:560-564.

Ivanicka, J. 1987. In vitro micropropagation of mulberry, Morus nigra L. Scientia Hort. 32:3339.

Kerns, H.R. and M.M. Meyer, Jr. 1986. Tissue culture propagation of Acer $\times$ freemanii using thidiazuron to stimulate shoot tip proliferation. HortScience 21:1209-1210.

Lentini, Z., H. Mussell, M.A. Mutschler, and E.D. Earle. 1988. Ethylene generation and reversal of ethylene effects durine dcvelopment in vitro of rapid-cycling Brassica campestris L. Plant Sci. 54:75-81

Lloyd, G. and B: McCown. 1980. Commerciallyfeasible micropropagation of mountain laurel, Kalmia Zatifolia by use of shoot-tip culture. Combined Proc. Intl. Plant Prop. Soc. 30:421427.

image density per explant in most of test species (Fig. 5). The rate of shoot initiation from explants was favored by horizontal placement for all species. Horizontal and vertical explants produced shoots of similar length, with the exception of Forsythia, which had shorter shoots from vertically placed explants.

Conclusion. The most striking factor affecting microshoot quality in these experiments was vessel size. Shoots with significantly greater image density and higher rooting capacity were produced in the two larger vessels. The tendency of the larger
MacDonald, B. 1986. Practical woody plant prop agation for nursery growers. Timber Press, Portland, Ore.

Mackay, W.A. and S.L. Kitto. 1988. Factors affecting in vitro shoot proliferation of French tarragon. J. Amer. Soc. Hort. Sci. 113:282-287.

Monette, P. 1986. Micropropagation of kiwifruit using non-axenic shoot tips. Plant Cell, Tissue \& Organ Cult. 6:73-82.

Murashige, T. and F. Skoog. 1962. A revised medium for rapid growth and bioassays with to497. bacco tissue cultures. Physioi. Plant. 15:473- 
Perl, A., D. Aviv, and E. Galun. 1988. Ethylene and in vitro culture of potato: Suppression of ethylene generation vastly improves protoplas yield, plating efficiency and transient expression of an alien gene. Plant Cell Rpt. 7:403 406.

SAS Institute, Inc. 1985. SAS user's guide: Statistics. 5th ed. SAS Institute, Inc. Gary, N.C.
Smith, M.A.L., L. Art Spomer, M.J. Meyer, and M.T. McClelland. 1989. Non-invasive evaluation of growth during plant micropropagation. Plant Cell, Tissue \& Organ Cult. 19:91-102. Sutter, E.G. and P.B. Barker. 1985. In vitro propagation of mature Liquidambar styraciflua. Plant Cell, Tissue \& Organ Cult. 5:13-22.

Thorpe, T.A. and K.R. Patel. 1984. Clonal prop- agation: Adventitious buds, p. 49-60. In: I.K. Vasil (ed.). Cell culture and somatic cell genetics of plants. vol. 1. Academic, New York. Webb, D.T., W. Arias, and E. de Hostos. 1986. Callus formation by Ginkgo biloba embryos on hormone-free media controlled by closures and media components. Phytomorphology 36:121127. 